\title{
Technology-enhanced science learning through remote laboratory: System design and pilot implementation in tertiary education
}

\author{
Siew Wei Tho \\ The Education University of Hong Kong, Hong Kong SAR \\ Sultan Idris Education University, Malaysia \\ Yau Yuen Yeung \\ The Education University of Hong Kong, Hong Kong SAR
}

\begin{abstract}
This paper reports the research on the successful development of a new remote laboratory $(\mathrm{RL})$ system through some innovative ideas and methods for practising technology-enhanced learning of science education. The Internet-based RL system enables learners to control and observe the server-side laboratory equipment as well as perform real-time scientific investigation activities at distant places. As a pilot implementation study, a set of newly developed remote experiments were first tried out by a total of 64 undergraduate students in a tertiary institution mainly for teacher education. The evaluation used a mixed research method which included a questionnaire survey, open-ended questions and interviews as specifically developed by us to collect data on students' perceptions, views and implementation issues related to the use of the RL system. The survey findings show that the participants agreed with the appropriateness of various educational merits of the RL system and the ways of conducting those innovative experiments. Furthermore, negative comments and suggestions for improvement were identified. Based upon these, we have refined our RL system and the RL design principles through an iteration of design-based research.
\end{abstract}

\section{Introduction}

With the rapid advancement of technology and the prevalent use of the Internet in education, science practical work in the form of a web-based laboratory or remote laboratory (RL) has recently been adopted in cloud computing. As a simple definition, the RL system serves "to enable students to conduct real world experiments at a distance” (Scanlon, Colwell, Cooper, \& Di Paolo, 2004, p. 154). Using this RL system, students can view and control apparatus/equipment in science experiments, and download real-time data in the classroom, computer laboratory or even at their home. Therefore, the RL can be considered as a kind of new development in technology-enhanced learning (TEL) in which appropriate technology and effective pedagogies are innovatively applied in science education.

The first part of this study designed and developed an innovative RL system through technology- enhanced inquiry for Hong Kong science education (Tho \& Yeung, 2014b, 2015). Of course, we are aware that it is hard to evaluate this innovative system based just upon the design or development itself. As a result, a pilot evaluation was conducted in two undergraduate classes as the second part of the study. For this pilot evaluation, we focused our analysis on the undergraduate students' views and suggestions for refinement of the RL system before its subsequent formal implementation and evaluation in secondary schools. The pilot evaluation was essential for ensuring the reliability of our research because students' views and suggestions were highly relevant to us, due to the fact that the participants studied various science education, ICT and teacher training courses. Furthermore, this new RL approach was appropriate for them in practising how to teach laboratory work and it could be applied in their future laboratory work in a school.

In essence, the RL system is composed of two major parts, namely hardware and software. The hardware consists of the data acquisition system, digital input or output, a digital camera, and various types of sensors. The software is used for data logging as well as control and display of the real-time experiment on the learner's computer screen via the Internet. The RL system can be applied for helping students learn scientific concepts comprised of topics from science discipline areas including physics and biology. In particular, the topics of "Plants" and "Electricity" by conducting inquiry experiments through the RL system were developed for the Hong Kong secondary schools science curriculum. 


\section{Need for the RL system for science practical work}

Scientists need to carry out experiments to test theories, whereas students need to conduct experiments to understand the theories. Therefore, "laboratories are essentially simulation environments where one can create various experiments and learning experiences” (Reddy, \& Goodman, 2002, p. 13). Moreover, the effectiveness of laboratory exercises in science education is recognised as crucial to understanding scientific concepts or knowledge (Abrahams, \& Reiss, 2012; Hofstein, \& Lunetta, 2004). Nagaraju (2008, p. 139) claims, "No course in Science can be considered as complete without including practical work in it." Therefore, practical work in a science laboratory is acknowledged as a fundamental part of science learning (Hofstein, \& Mamlok-Naaman, 2007; Nagaraju, 2008; Reddy, \& Goodman, 2002; Tho \& Yeung, 2014a).

According to research in science education, there are numerous issues and difficulties in employing laboratory work for effective learning and teaching of science in schools, especially in Hong Kong. Firstly, lack of sufficient time allocated for learning and teaching in science education is a great challenge (Cheung, 2008). Therefore, its effect on students' chance of performing science experiments will be particularly significant for "experiments that take longer than a standard science lesson may frequently be ignored" (Souter, \& MacVicar, 2012, p. 11). Secondly, as a matter of learning diversity, slow-learning or underperforming students often need to spend a much longer duration on hands-on and minds-on learning activities, such as conducting real science experiments for school-based assessment and drilling on problem-solving exercises for public examinations (Yeung, Lee, \& Lam, 2012). Thus, it is vital to allow students to engage in those learning activities during their free or leisure time - usually outside the school environment.

However, there are no such real and hands-on experiments that let students conduct science practical work during their free time. Additionally, the laboratory work normally requires the student to conduct the experiment in school science laboratories, which represents the third learning obstacle. Fortunately, the RL system can solve this problem by allowing students to carry out their learning during their free or leisure time at home or anywhere as long as a computer with Internet access is available, because the students need only a web browser (e.g., Internet Explorer or Google Chrome) to monitor and control the real-time experiment from their computer.

Lastly, the new experience of performing real-time practical work via the RL system could supplement, enrich and/or extend students' traditional practical activities in school. In other words, the RL system provides an alternative way of conducting real experiments out of school time.

\section{Literature review}

\section{Scientific inquiry and technology-enhanced laboratory work}

Recently, a new set of school science standards called “The Next Generation Science Standards” (NGSS) has been implemented in the USA. The frame of the NGSS is established in accordance with the core ideas in the major fields of natural science from A Framework for K-12 Science Education: Practices, Crosscutting Themes, and Core Ideas (National Research Council [NRC], 2012). There are three important dimensions that can be derived from the framework, namely practices, core disciplinary ideas, and crosscutting concepts. In particular, the practices dimension is directly related to practical work. According to the NGSS, "[we] use the term "practices" instead of a term such as "skills" to emphasize that engaging in scientific investigation requires not only skill but also knowledge that is specific to each practice." (NRC, 2012, p. 30).

Regarding practices in science and engineering, there are eight important elements to engage all students in science learning, as listed below (NRC, 2012, p. 49):

(1) Asking questions (for science) and defining problems (for engineering).

(2) Developing and using models.

(3) Planning and carrying out investigations.

(4) Analysing and interpreting data.

(5) Using mathematics and computational thinking.

(6) Constructing explanations (for science) and designing solutions (for engineering).

(7) Engaging in argument from evidence. 
(8) Obtaining, evaluating, and communicating information.

Conventionally, science practical work requires students to follow specific procedures and solve specific questions provided in a laboratory manual. It is more typically known as a cookbook or recipe experiment. Furthermore, a longer time is required to manually conduct these routine tasks, including the recording the data, graph plotting, and data analysis. Specifically, Gallet (1998) pointed out that:

Recipe experiments tend to sterilize imagination and initiative, leave no room for hypothesis, trials, errors, individual responsibility in a group, and above all, preclude the student's involvement in a decision-making process - which is so important to our modern society. In other words, many parameters that are fundamental to the scientific method are left out by the macroscale cookbook formula approach. (p. 73)

However, it would be an entirely different situation if a learner is allowed to integrate inquiry learning with TEL using the data logger or computer-based laboratory (CBL) system. For example, Baker (2007) conducted a study to apply the data logging system in indoor, outdoor, or underwater environments and concluded that it is "ideal for applications with field studies, transportation monitoring, high voltage tests, troubleshooting, quality studies, general research and educational science” (p. 21).

A data logger (also called datalogger, data acquisition, or data recorder) is an electronic digital device that records data with instruments or sensors and often allows instantaneous display of data in graphical or tabular form. These sensors can be connected externally or built internally in the data logger, and all routine jobs are computerised, thereby saving time for other activities (Barton, 2004; Ng \& Yeung, 2000; Taylor, 1997; Tho \& Hussain, 2011). Several important characteristics of the data-logging process have been summarised by $\mathrm{Ng}$ and Yeung (2000, p. 3) as follows:

Data-logging is a trend in practical activities in science education. Its major advantages are the high sensitivity for measurement of very small changes and the ability to monitor changes over a very short or a very long period of time. It can record and store data of one or more parameters. The variations of several parameters can be shown on the same graph for comparison of trends and analysis for inter-relationship. As the recording and the presentation of data are automatic, time can be saved for repeating the experiment with different settings and parameters.

Furthermore, computer-based practical work can encourage and induce students to create and answer their own "what if" questions, rather than blindly following the instructions given in the laboratory manual (Barton, 2004). The new learning approach is made possible by the fact that the CBL can efficiently reduce the time needed in conducting experiments, enabling more time for interpreting or evaluating data. Thus, students can engage in more higher-order thinking activities, such as improving their experimental design skills or modifying existing experiments using their creativity and critical thinking skills. Steinberg (2003) claimed that the CBL approach provides science teachers with more opportunities to engage students intellectually and to explore more meaningful and exciting subject matters.

\section{RL for science education}

Despite the many educational merits of practical work in science education, the traditional way of providing these practical activities may have a number of severe limitations, such as long set-up time, resource depletion, requirement of laboratory space and teachers' inadequate experimental practices and safety. Besides, students may lack sufficient knowledge, practices and safety training to conduct the practical work effectively and safely. However, these limitations or problems could be resolved by the use of RL in experiments. For example, expensive equipment can be shared among institutions, and the risks or dangers of carrying out experimental work by students in person can be largely eliminated (Grober, Vetter, Eckert, \& Jodl, 2007). Additionally, the benefits of access to remote experimental equipment were identified by Cooper and Ferreira (2009, p. 352) as follows:

- enabling distance learning

- $\quad$ sharing use of high cost and complex experimental equipment

- $\quad$ efficiently handling the increasing number of students with limited laboratory space. 
However, conducting experiments through the RL system will not be a perfect solution because the RL activities may be affected by certain constraints or problems, such as Internet annoyances (e.g., connection problems and hacking) and limited numbers of learners for controlling or observing the experiment at the same time. Besides, RL is normally connected with "specific apparatus which is not available in normal laboratories. As a result, the investigation is limited to a few experiments tied to the apparatus. It is not designed to support a high degree of openness." (Chen et al., 2012, p. 8). Some of those problems can be partially solved by an appropriate refinement of the design and development of the RL system.

A number of previous studies on RL system development anticipated that these remote-controlled technologies may play an important role in the science and engineering learning process (Barrios et al., 2013; Scanlon et al., 2004; Tiwari \& Singh, 2011). For example, some innovative remote experiments are freely available on the Internet:

- $\quad$ iLabs (Jona, Roque, Skolnik, Uttal, \& Rapp, 2011; Sauter, Uttal, Rapp, Downing, \& Jona, 2013)

- $\quad$ the remote radioactivity experiment initiated by Jona and Vondracek (2013)

- $\quad$ VISIR (Virtual Instrument Systems in Reality) introduced by Gustavsson et al. (2009) and Tawfik et al. (2013)

- $\quad$ iSES (internet Schools Experiment System) for related physics experiments created by Schauer, Lustig, Dvořák, and Ožvoldová (2008)

- $\quad$ Labshare project (Lowe, Newcombe, \& Stumpers, 2013).

However, these RL systems may not be suitable for applying directly to undergraduate students in teacher education institutions as they need to follow the science syllabus in school. In other words, the existing remote experiments are too advanced and are neither designed for the school science syllabus that the students are going to teach nor to be used as teaching kit in school. So far, most published papers focus on technical issues in engineering development and lack a rigorous evaluation of students' learning effectiveness and their attitude towards the new mode of learning (Gillet, Ngoc, \& Rekik, 2005; Hercog, Gergič, Uran, \& Jezernik, 2007; Ko, Chen, Chen, Zhuang, \& Tan, 2001). As this approach is still uncommon in the school science learning environment, there is limited empirical evidence available to verify if this technology can be used effectively as a tool for facilitating and helping students develop their science learning (Kong, Yeung, \& Wu, 2009; Lowe et al., 2013; Sauter et al., 2013). Thus, this study aims to provide pilot research findings on the educational merits of science learning among undergraduate students after undergoing some science practical work via the newly developed RL system. The present study investigates whether undergraduate students are able to actively and confidently engage in science learning and teaching through the RL system.

\section{Research methodology}

In developing and designing the RL package, the design-based research (DBR) framework was adopted in this study. Anderson and Shattuck's (2012) review article on DBR critically scrutinised the use of DBR over the past decade. They found that there is an increased use of the DBR framework for related technology-enhanced research papers. In addition, an important element of DBR is to "build a stronger connection between educational research and real world problems” (Amiel, \& Reeves, 2008, p. 34). The core idea of this framework is to integrate technology with real-world settings in education (Amiel, \& Reeves, 2008; Kong et al., 2009; Reeves, 2006). The DBR framework consists of continuous cycles that normally follow four major steps, namely design, enactment, analysis, and redesign (Collins, 1992; DesignBased Research Collective, 2003). Therefore, the DBR method does not attempt to find universal explanations or solutions; instead, it helps to discover a deep understanding of innovations and the issues that may affect development in real settings (Anderson, 2005). In other words, using this framework allows a detailed evaluation of, and improvement towards, the newly developed system to be performed. In similar wordings, Feng and Hannafin (2005, p. 6) defined DBR as "a systematic but flexible methodology aimed to improve educational practices through iterative analysis, design, development, and implementation, based on collaboration among researchers and practitioners in real-world settings".

Since the DBR method is a flexible methodology which provides in-depth understanding of the adoption of innovation, we modified the DBR method in educational technology research as proposed by Reeves (2006) and adapted it with the main purpose of developing and designing the RL system for secondary science education. Our adaption involves four important stages but with modification of the iteration cycle in the third stage, as shown in Figure 1. 


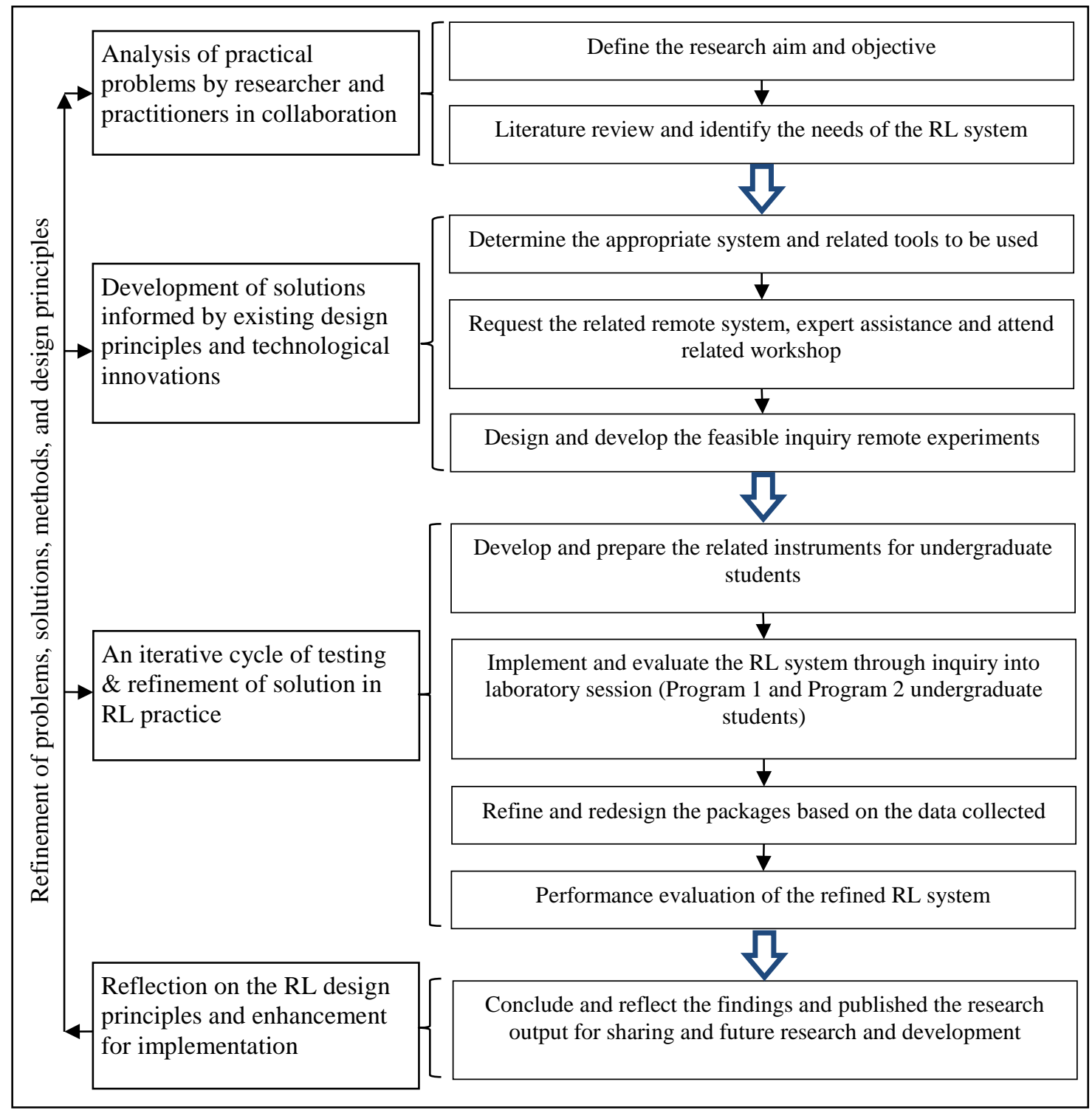

Figure 1. Research framework using the DBR process (adapted from Reeves, 2006, p. 59)

\section{Analysis of practical problems by researcher and practitioners in collaboration}

The first stage of this study comprised the discovery of the related literature and analysis of the practical problems or needs of the laboratory work in the Hong Kong region. With past experience as a science teacher (first author) and now as science teacher educators with a research interest in technology-enhanced science laboratory learning, we discovered that it is essential to understand what implications this state-ofthe-art RL technology has for practical work in science education.

Relevant practitioners were asked to give feedback on the conventional science laboratory. The data collected from the practitioners were analysed for positive and negative themes. Then, the same practitioners in collaboration were asked to provide critical reflections after the iteration process. This is an important process of DBR by involving users in the development and design process through their views, comments and suggestions concerning the difficulties faced.

\section{Development of solutions informed by existing design principles and technological innovations}

The learning theory of constructivism concerns how the learner actively constructs his/her own knowledge based on interpretation in response to interactions with certain learning environments or methods (Jonassen, 
1999). For science laboratory work, students are required to actively participate and explore certain science knowledge through their laboratory activities (Roth, 1994). Torre et al. (2013) claimed that the RL can be considered as a constructivist method. In addition, the RL can provide the social constructivism learning environment for conducting remote experiments and sharing the experimental data among users at different places (Abdulwahed \& Nagy, 2011). In this study, the new RL for science education was originally created as a guided constructivist learning environment that allowed students to actively engage and investigate remote science experiments. Through using this RL approach, students have an excellent opportunity to experience constructivist science learning as embedded in their laboratory practice.

A Google Scholar search yielded no literature addressing the design principle and criteria of RL in secondary science education. However, several design principles of RL in the engineering area were able to be revised and borrowed in the current study. It is difficult to totally adapt the identical RL design principles from engineering directly into science education. Out of the several existing RL design principles, we adopted four essential ones with modification for the design of the RL system as follows:

- Integration with the science education curriculum: The learner activities through the newly developed RL package must integrate and align to the science education curriculum.

- Interactive learning: The RL package must be real-time and interactive.

- $\quad$ Learner engagement: The RL package must engage the learner in technology-enhanced inquiry with motivation.

- Wide range of learner ability: The RL package must be suitable across a wide range of learner ability and available at any time as well as anywhere.

Then, we tested several existing online experiments and attended classes and workshops. This constituted the process of identifying the appropriate system; that is, innovative use of Internet Protocol (IP) camera, Internet School Experimental System (Schauer et al, 2008), the open source RL using LabVNC and the RL of the National Instruments (NI) system) and related experimental tools as well as potential science topics.

Consequently, the appropriate remote technology system was selected. This involved several important steps, such as (a) purchasing the NI products, Laboratory Virtual Instrument Engineering Workbench (LabVIEW) software, and IP camera and (b) attending related NI workshops in early 2013 as well as (c) seeking expert assistance.

Feasible experiments which could be incorporated into the RL system were identified from a critical review of the local school science curricula. The development of new RL system also included the calibration of sensors, software development, and design of the complete remote-controlled experimental set-up for an array of scientific investigation experiments.

\section{An iterative cycle of testing and refinement of solutions in RL practice}

An iterative cycle of testing and refinement of the RL system was performed. For testing and evaluation, 69 undergraduate students in two different types of science-related teacher education programs voluntarily participated in this mixed method research. First, a set of RL system guidelines and newly developed technology-enhanced inquiry worksheets were distributed during their laboratory sessions. Second, a briefing session of the related worksheets and on how to use the RL system was given by the researcher, including an RL system that could be accessed by students to manipulate or control real-time experiments via the Internet. Third, students then accessed the RL system and performed the remote experiments based on the worksheets given. Lastly, once the remote experiments were completed by the students, the related evaluation was conducted.

A self-developed survey questionnaire with four Likert scale and open-ended questions, as well as an interview, were used to collect participants' views on the advantages and disadvantages of conducting remote experiments, based on their learning experiences, in addition to their perceptions, attitudes, issues and feedback of science learning and teaching through the RL system. However, no cognitive test was used in this DBR study as the students' cognitive understanding of the science concepts is not the main concern of this study. The questionnaire instrument included questions on eight categories of educational merits on using the RL system for science learning and teaching. Through this iteration of DBR, we have refined both of our RL system and design principles. Subsequently, the performance evaluation of the refined RL system was conducted for testing the system stability and response time experienced by users. 


\section{Reflection on the RL design principles and enhancement for implementation}

Even though only one iterative cycle of testing and refinement has been performed, it is still worthwhile to reflect on our own responses on the RL learning process with the intention of refining the RL system and producing design principles that can enlighten future development by other researchers to enhance the suggested approach of implementation. Through this DBR process, the refined RL system is considered as the main output that can be shared and published.

\section{Findings and discussion}

\section{RL system}

For the RL system development, four feasible experiments (Table 1) that can be incorporated into the RL system were successfully developed with reference to the local school science curricula. Figure 2 concisely outlines the design of the RL system for performing remote-controlled experiments with the aid of an IP camera and NI system. The NI system includes the LabVIEW software, which is a graphical programming language that uses icons rather than lines of text to generate programs. It is equipped with the data acquisition hardware and remote control application through a web publishing tool. Therefore, new remotecontrolled experiments were developed by mostly using the LabVIEW (version 2011 SP1) software and the NI hardware modules to control the instrument through a server computer which allows students remote access via the Internet.

Table 1

The design and content of remote-controlled experiments

\begin{tabular}{|c|c|c|}
\hline Experiment & Learning objective & Changing parameter \\
\hline $\begin{array}{l}\text { E1: Sound as vibration } \\
\text { (jumping beans) }\end{array}$ & $\begin{array}{l}\text { Understand the nature of sound } \\
\text { as vibration. }\end{array}$ & $\begin{array}{l}\text { Wave type, sound frequency and } \\
\text { volume. }\end{array}$ \\
\hline $\begin{array}{l}\text { E2: Electrical circuit (series } \\
\text { and parallel) }\end{array}$ & $\begin{array}{l}\text { Understand the series and } \\
\text { parallel circuit connections. }\end{array}$ & $\begin{array}{l}\text { Number of bulbs in series and } \\
\text { parallel. }\end{array}$ \\
\hline $\begin{array}{l}\text { E3: Plant experiment - } \\
\text { Phototropism }\end{array}$ & $\begin{array}{l}\text { Long-time observation of plant } \\
\text { with light source. }\end{array}$ & $\begin{array}{l}\text { Three positions of light source } \\
\text { and plants' vertical axis of } \\
\text { rotation. }\end{array}$ \\
\hline $\begin{array}{l}\text { E4: Plant experiment - } \\
\text { Gravitropism }\end{array}$ & $\begin{array}{l}\text { Long-time observation of plant } \\
\text { due to effects of gravity. }\end{array}$ & $\begin{array}{l}\text { Plants' horizontal axis of rotation } \\
\text { at } 30^{\circ} \text { or continuously. }\end{array}$ \\
\hline
\end{tabular}

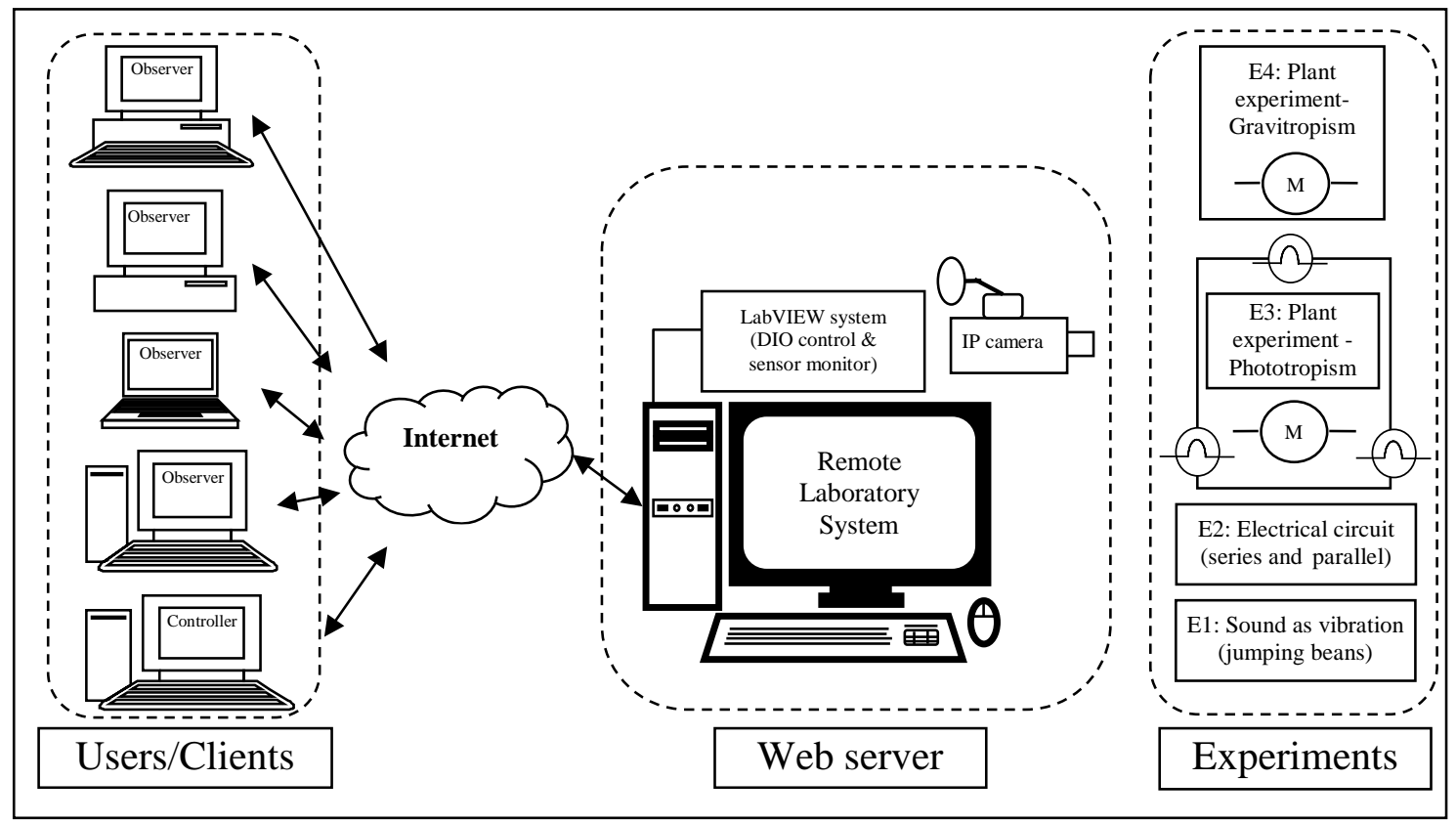

Figure 2. Structure of the RL system for performing science experiments 
Figure 3 shows the web page for the E4 plant experiment on gravitropism to be conducted by students. The experimental set-up and the movie for those experiments can be found online at http://rcl.ied.edu.hk:8000/sample/index.htm, and the web page demonstrates how this remote technology is employed.
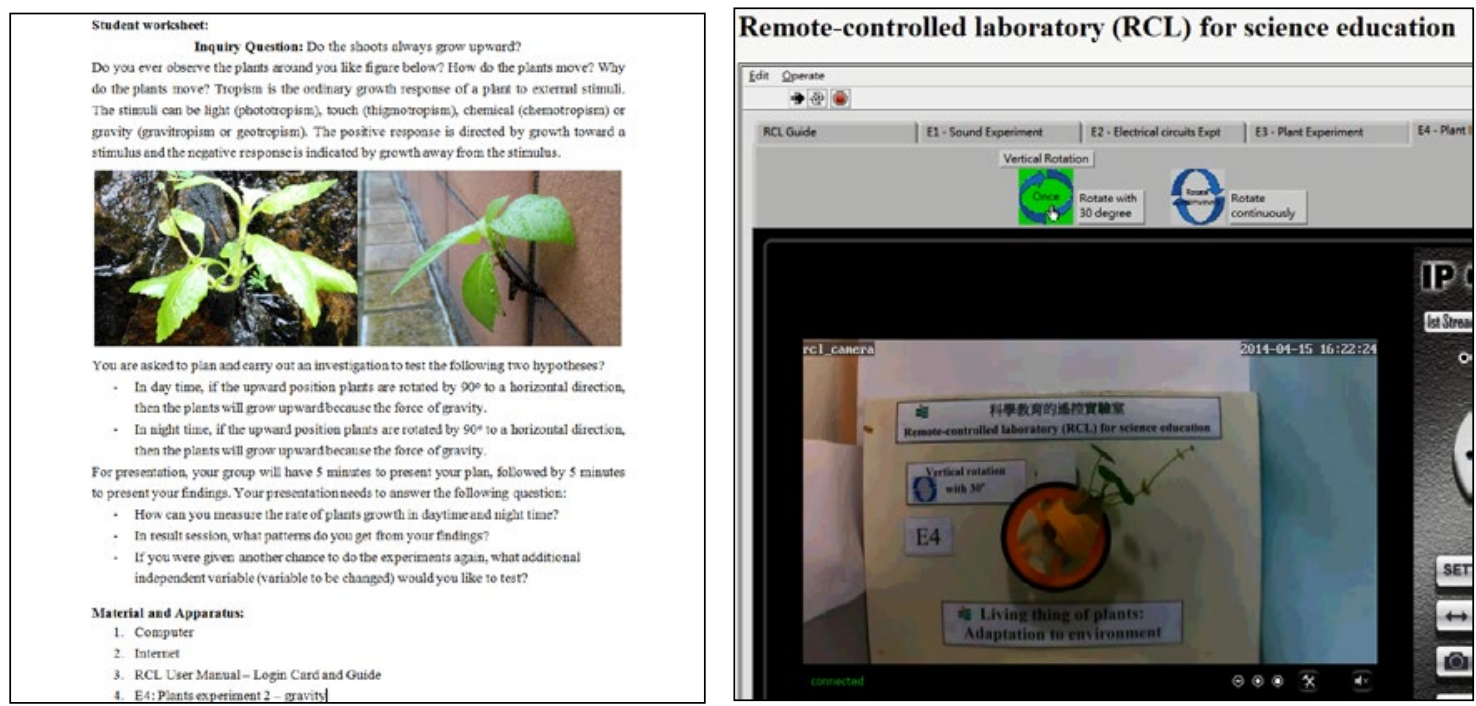

Figure 3. (left) Student's worksheet; (right) Web page display of the RL system for the gravitropism experiment

\section{Participants}

This evaluation study was conducted in a tertiary teacher education institution. A total of 69 third-year undergraduate students in two different types of program - Program 1 (Science and Web Technology) and Program 2 (Science-related Teacher Training) - were asked to participate in the evaluation process of this RL approach. To comply with the educational research code, they were required to complete and sign a consent form for their voluntary participation in the research. However, only 64 sets of collected data were valid for the subsequent statistical analysis process. Table 2 shows the descriptive statistics of the participants.

Table 2

Descriptive statistics of the participants in program versus gender cross-tabulation

\begin{tabular}{lccc}
\hline \multicolumn{1}{c}{ Class } & Gender & Total \\
& Male & Female & \\
\hline Program 1 & 20 & 10 & 30 \\
Program 2 & 24 & 10 & 34 \\
\hline Total & 44 & 20 & 64 \\
\hline
\end{tabular}

\section{Comparison of participants' perceptions of conventional science laboratory and RL approaches}

Before the implementation, participants were asked to give feedback on the conventional science laboratory. As practitioners, these data were important to us for exploring the current uses and problems of laboratory learning. The responses indicate that the current laboratory learning faced several problems, such as large experimental errors, no possibility to conduct dangerous experiments, and the challenge of timing when conducting science practical work (i.e., experimental set-up and recording). These comments were subsequently used for comparison with the comments on the RL to obtain a more comprehensive view of the application of the innovative remote experiments into science education. The comments were input for coding into the NVivo software, and themes based on students' previous and current learning and experience of laboratory work (i.e., conventional science experiments and the remote-controlled laboratory) were derived (see Table 3). 
Table 3

Participants' most frequent comments on RL and conventional laboratory work $(N=64)$

\begin{tabular}{|c|c|c|}
\hline & Conventional science laboratory & $\mathrm{RL}$ \\
\hline $\begin{array}{l}\text { Positive } \\
\text { comments* }\end{array}$ & $\begin{array}{l}\text { - } \text { Real hands-on experiments (34) } \\
\text { - } \text { Able to understand the scientific } \\
\text { principles or knowledge (18) }\end{array}$ & $\begin{array}{l}\text { - Able to conduct experiments at anytime (21) } \\
\text { - RL is interesting (14) } \\
\text { - Able to conduct experiments at any place (13 } \\
\text { - Able to conduct experiments at real-time via } \\
\text { the Internet (11) }\end{array}$ \\
\hline $\begin{array}{l}\text { Negative } \\
\text { comments* }\end{array}$ & $\begin{array}{l}\text { - Time consuming for students to set } \\
\text { up and record the experiments (31) } \\
\text { - Certain experiments are dangerous } \\
\text { (11) } \\
\text { - Large experimental errors (11) }\end{array}$ & $\begin{array}{l}\text { - } \text { Cannot touch the equipment or tools (17) } \\
\text { - Internet problem (14) } \\
\text { - Set-up problem (12) } \\
\text { - } \text { Need time to learn new way of conducting } \\
\text { experiment (10) }\end{array}$ \\
\hline
\end{tabular}

*Similar comments which occurred more than 10 times were summarised and sorted from most common to least common (with frequencies in brackets).

After the implementation, participants were also asked to give feedback on the RL. They found the RL system to be interesting and they were able to conduct real experiments via the Internet anywhere and at their leisure. However, participants did not have a chance to physically touch the experimental equipment or tools - which is quite different from work in a conventional science laboratory. In addition, they encountered problems with Internet connection and set-up, as required in this new way of conducting science experiments. Generally speaking, those findings are consistent with the results obtained by previous researchers such as Chen et al. (2012), Cooper, and Ferreira (2009), and Lowe et al. (2013), who also pointed out some advantages and disadvantages of using the RL from studying their research and participants' work. Therefore, this RL approach has the potential to develop a new field of laboratory work which can prepare undergraduate students in tertiary teacher education institution to apply this technique in their future teaching career, particularly in schools.

\section{Survey and interview data}

Table 4 reports the evaluation data of the independent samples $t$-test as obtained from the student survey. For the eight categories on the educational merits of the new RL approach based on the program of study, the mean scores (with a Likert scale of $1=$ strongly disagree, $2=$ disagree, $3=$ agree and $4=$ strongly agree) lay within the range of 2.73 to 3.14, and the score for every category was close to the scale of 3 for agreeing with the questionnaire statement. The Cronbach's alpha reliability coefficient of the survey was 0.96. Note that the analysis of those Likert responses was based on the classical test theory, which assumes equal interval between response points. A better approach is to apply item response theory or Rasch modelling, but they require a much larger sample size for valid calculation. Given that it is a pilot study, it should be good enough to adopt the classical test theory for the present data analysis. Based on the findings, the Program 2 participants constantly rated higher in the survey items compared to Program 1 participants, although there were no significant differences found by the independent samples $t$-test except the "stimulating motivation" category. The $t$-test also revealed that there was no statistically significant gender difference.

Overall, the survey findings from all participants show that they agreed with the educational merits underlying the RL system in the present study and the ways of performing the Internet-based science experiments. The RL was perceived to improve their confidence level of teaching ("enhancing self-efficacy in learning and teaching” category) and as a useful tool for learning and teaching science. Then, an independent samples $t$-test was used to compare the scores given by students in programs 1 and 2 and a statistically significant difference was found for the "stimulating motivation" category at .05 significance level, where Program 2 participants were found to be generally more motivated in the session conducting RL experiments than Program 1 participants (see Table 4). It was anticipated that participants who studied fewer ICT courses were more motivated in testing and using the RL system. In addition, the lowest overall mean score given by participants is the "promoting group work" category. However, the difference between the mean score of this category and that of the highest one is just 0.2 , which is $2-3$ times less than the standard deviation of any item, indicating a statistically insignificant difference between mean scores of different categories. 
Table 4

Mean scores (with SD in brackets) and t-test of participants' response on survey items listed by program

\begin{tabular}{lcccc}
\hline \multicolumn{1}{c}{ Category } & Program $1(N=30)$ & Program $2(N=34)$ & Overall $(N=64)$ & $t$ statistic \\
\hline $\begin{array}{l}\text { Insight of science \& } \\
\text { ICT }\end{array}$ & $2.91(.55)$ & $2.98(.64)$ & $2.95(.60)$ & -.46 \\
$\begin{array}{l}\text { Operating the RL } \\
\text { system }\end{array}$ & $2.90(.50)$ & $3.06(.42)$ & $2.98(.46)$ & -1.38 \\
Enriching the learning & $2.82(.89)$ & $3.03(.59)$ & $2.93(.75)$ & -1.08 \\
Developing application & $2.78(.66)$ & $2.99(.52)$ & $2.89(.59)$ & -1.42 \\
Stimulating motivation & $2.80(.78)$ & $3.14(.54)$ & $2.98(.68)$ & $-2.03^{*}$ \\
Improving teaching & $2.87(.65)$ & $3.06(.45)$ & $2.97(.56)$ & -1.39 \\
skills & & & & \\
Promoting group work & $2.73(.73)$ & $2.97(.57)$ & $2.86(.66)$ & -1.45 \\
Enhancing self-efficacy & $2.81(.67)$ & $2.99(.45)$ & $2.90(.56)$ & -1.24 \\
in learning and teaching & & & & \\
\hline
\end{tabular}

Note: ${ }^{*} p<.05$

The participants were also asked to rate their present level of science knowledge. Table 5 reports the evaluation data of analysis of variance (ANOVA) as obtained from the student survey. For the eight categories on the educational merits of the new RL approach, the mean scores lay within the range of 2.75 to 3.31 as based on the science knowledge level. Overall, participants with a low level of science knowledge constantly rated higher in the survey items than those with a medium or high level of science knowledge for all categories except "insight of science and ICT" and "enhancing self-efficacy in learning and teaching". Then, an ANOVA test was used to compare the scores given by students in their science knowledge level. Surprisingly, a statistically significant difference was found for the "operating the RL system” category at .05 significance level. Participants with a low science knowledge level were generally found to have more easily worked in the sessions conducting RL experiments than medium and high level participants (see Table 5). Consequently, a statistically significant difference was also found for the "stimulating motivation" category at .05 significance level, where participants with a low science knowledge level were also found to be generally more motivated in the session conducting RL experiments than the participants from the other two groups of levels (see Table 5). The participants who rated a low science knowledge level were more motivated and more easily operated the RL system. Thus, the findings represent an important outcome of the RL activities as the RL can effectively motivate the low achiever in science to use this method for teaching and learning. However, due to the relatively smaller number of participants in each group, we could not draw any statistically significant conclusion.

Table 5

Mean scores (with SD in brackets) and ANOVA test of participants' responses on survey items based on science knowledge level

\begin{tabular}{lcccc}
\hline \multicolumn{1}{c}{ Category } & $\begin{array}{c}\text { High } \\
(N=11)\end{array}$ & $\begin{array}{c}\text { Medium } \\
(N=35)\end{array}$ & $\begin{array}{c}\text { Low } \\
(N=18)\end{array}$ & $F$ statistic \\
\hline Insight of science and ICT & $3.15(.54)$ & $2.84(.64)$ & $3.04(.52)$ & 1.45 \\
Operating the RL system & $2.88(.54)$ & $2.90(.43)$ & $3.22(.41)$ & $3.60^{*}$ \\
Enriching learning & $3.09(.75)$ & $2.78(.73)$ & $3.13(.76)$ & 1.62 \\
Developing application & $2.88(.73)$ & $2.80(.58)$ & $3.07(.52)$ & 1.28 \\
Stimulating motivation & $2.85(.77)$ & $2.85(.72)$ & $3.31(.40)$ & $3.28^{*}$ \\
Improving teaching skills & $2.94(.53)$ & $2.90(.61)$ & $3.13(.44)$ & 1.08 \\
Promoting group work & $2.79(.75)$ & $2.75(.68)$ & $3.11(.50)$ & 1.90 \\
Enhancing self-efficacy in & $3.02(.51)$ & $2.83(.53)$ & $2.97(.66)$ & .61 \\
learning and teaching & & & &
\end{tabular}

Note: ${ }^{*} p<.05$

For qualitative data analysis, the open-ended data from the survey was input for coding into the NVivo software, and themes based on four open-ended questions on learning, difficulties, improvements and suggestions. Subsequently, semi-structured and tape-recorded interviews with three randomly selected participants from Program 1 were arranged after the RL learning. The coding and derived themes were based on content of the remote experiments, difficulties encountered, and suggestions. 
For open-ended questions, the participants' feedback on their views, perception and difficulties of using the RL system were collected (see Table 6). It is noted that a number of negative comments and suggestions were also listed for RL system refinement. These negative comments or limitations of the RL activities are unavoidable but they can be alleviated or resolved with appropriate refinement in the design and development of the system. Moreover, the study shows that participants need to receive sufficient guidance and training to use the RL system to optimise its educational values. Nevertheless, some features of the RL system have to be amended and technical problems need to be overcome to provide a more reliable and robust system. Further studies could focus on using a high resolution IP camera for observation and developing a simpler and more user-friendly interface suitable for secondary school students.

Table 6

Four open-ended questions to assess participants' perceptions of the RL system $(N=64)$

\begin{tabular}{ll}
\hline Open-ended question & Selected insightful comments* \\
\hline $\begin{array}{ll}\text { 1. What have you learned from } \\
\text { the inquiry experiments }\end{array}$ & - They learned how to conduct experiment through RL system \\
through the use of RL system? & - They learned related scientific concepts (13) \\
2. Have you encountered any & - They faced the Internet problem (18) \\
$\begin{array}{l}\text { problems concerning the } \\
\text { system equipment while doing }\end{array}$ & - They faced the set-up problem (13) \\
the inquiry experiments? & - They faced problems of controlling the IP camera with other \\
3. If you were given another & - Thers (8) \\
$\begin{array}{ll}\text { chance to do the experiments } \\
\text { again, please suggest some }\end{array}$ & - They suggested using high resolution IP camera (13) \\
ways for improvement. & - They suggested using Smartphone (2) \\
4. Please suggest a science & - They suggested time allocation for group work (2) \\
topic/activity that is possible to & photosynthesis, plants and animal behaviour] (19) \\
apply the inquiry experiments & - They suggested physics topic [electricity and dangerous \\
via the use of RL system. & experiment: heat and radioactivity] (15) \\
& - They suggested chemistry topic [chemical reaction] (5)
\end{tabular}

* The comments sorted from most common to least common (with frequencies given in brackets).

The interview after the laboratory session also gave extensive, meaningful and more in-depth data about the students' views and suggestions on the use of the new RL system that can be triangulated from the survey. To preserve anonymity, participants in the interviews have been given referred to as A, B and C. Based on the interview, participants also reflected that this new RL helps them clearly understand the importance of remote experiments, and that it is great to use the RL system in observing and understanding the nocturnal behaviour of plants. However, some shortcomings and suggestions of the RL were also identified (see Table 7).

Table 7

Summary of participants' feedback on the RL in the interviews

Positive comments: A: "Increase student learning motivation because student can observe and control the remote experiment."

B: "For certain night-time science experiment, we can observe it at anyplace." C: "Save time. Previously, we need to stay and wait for recording the whole day science experimental data. But, we can record the data at anytime and anywhere through the use of RL system."

Negative comments: A: "Operating the remote experiment is relatively clumsy."

B: "The user interface is difficult to control."

C: "The lack of real hands-on in remote experiment in comparison with the traditional experiment."

Suggestions: $\quad$ A: "High resolution of IP camera and high speed of Internet bandwidth are needed."

B: "Through an easy user interface, you can control a lot of other parameters." C: "For secondary school, do some radioactivity experiments." 


\section{RL system refinement}

Based on the analysis of data collected, we refined the RL system in the following ways:

- $\quad$ using a higher resolution IP camera

- modifying existing remote experiments

- adding new feasible remote experiments (plant respiration, battery bank, infrared application of night vision and solar energy)

- providing clearer RL operating guidelines

- $\quad$ arranging the time of conducting the remote experiments

- improving the collaboration in learning by adding a free synchronous chat box.

For the performance evaluation of the refined RL system, we discovered that the refined RL system could be controlled by one user and four observers simultaneously. As well, the response time experienced by a controller for performing the remote experiments was acceptable. The adaptation of the high resolution IP camera caused a two-second delay, but this problem could be overcome by setting the camera video view to mobile view. The RL design principles and reflection are presented in the following section.

\section{RL design principles for science education}

For the design and implementation of a new RL system in science education particularly at the secondary level, four RL design principles should be used as mentioned in the earlier section. Based on the present findings, two additional RL design principles were considered to be important in the development of a new RL system for science education, namely collaboration in learning and RL instruction. For collaboration in learning, the RL package must include synchronous chat and messaging functions that can promote students' teamwork (Cooper, \& Ferreira, 2009). For RL instruction, the RL package must provide clearer RL operating guidelines and worksheets for better understanding of the remote experiments (Kirschner, Sweller, \& Clark, 2006; Tiwari, \& Singh, 2011).

\section{Reflection}

As practitioners and researchers in this RL research and development, we noticed that the development of this new RL system is actually a quite complex process, in which researchers need to not only develop a new reliable RL system for science education, but also to evaluate it through various types of research instrument in order to explore learners' perceptions of and attitudes towards the learning and teaching processes. We are very glad that most of the participants in this study were able to identify both favourable and unfavourable aspects of this new RL system. On the favourable side, the participants agreed with the specific educational merits of the new RL system and felt confident in using the RL system in their future learning and teaching (as based on the survey and interview data). Therefore, the findings are very encouraging to us as we expect the RL system to be not just promoting innovative remote experiments, but also exploring participants' perceptions, learning and future teaching experiences, particularly in laboratory work. On the other hand, unfavourable comments from the participants (i.e., Internet, set-up and visual problems) drove us to refine our RL system, especially for designing investigation activities which are closely related to the secondary science curriculum. Indeed, those negative comments are quite expected because some participants were not interested in using ICT for learning; the laboratory work via the RL system was new and challenging; and a rather short time was allocated for them to complete the required activities during their laboratory session. We obtained several helpful suggestions from this study, for example, more user guidelines, design of dangerous or uncomfortable experiments, and use of a high resolution camera. In a word, the collection and analysis of these valuable comments and suggestions are one of our major purposes in piloting the RL research in tertiary teacher education institution and they will form a very helpful basis for our future implementation of the refined RL system in secondary schools.

\section{Implications of a RL system in science education}

The results of this study show that the new RL system has great potential for the application of science laboratory learning in the school environment. Based on the present findings, analysis and refinement, there are three key implications of this study for the future development and school-based implementation of the RL system. First, the refined RL system itself is taken as our main tangible deliverable that can be shared, published and applied into science education. This system could be used for laboratory work and 
demonstration for enriching and extending science teaching and the learning process beyond the constraints of a traditional school environment. For developing this RL system, a set of design principles can be adopted and shared for future laboratory work development in science teacher professional development or secondary level. The RL design principles can be sorted into six domains or aspects of consideration: integration with the science education curriculum, interactive learning, learner engagement, wide range of learner ability, collaboration in learning, and RL instruction.

Second, the new refined RL system, and especially those remote experiments, was developed to integrate with secondary science education, including the physics and biology fields. So far, there have been rather limited RL-based experiments in physics and none in biology. In open-ended questions, the participants suggested more remote experiments related to physics and biology. Developments on remote experiments by previous researchers focused mainly in the engineering field (Barrios et al., 2013; Scanlon et al., 2004) with a few cases in secondary physics subjects (e.g., Schauer et al., 2008).

Third, the survey, open-ended questions and interview findings reveal that special attention must be given to RL instruction and guidance (Kirschner, Sweller, \& Clark, 2006). Participants demanded clearer RL operating guidance. This is likely due to the adoption of a new approach which is unfamiliar to them; therefore, more detailed guidance in RL operating procedures and student worksheets will be developed before implementing the remote experiments in secondary schools.

Last but not least, the refinement works for the RL system include a number of special or innovative features that should be incorporated to increase the likelihood of the system being adopted into the school learning environment:

- Reliability and robustness of the RL system must be ensured so that even careless users from schools will not damage the system.

- Access rights need to be properly managed and monitored so that related remote experiments can be shared from the teacher education institution to different schools.

- Efficient use of space by a refined RL system where remote experiments are comprised of eight topics from different science discipline areas.

\section{Conclusion and future work}

The present study has achieved several important outcomes. Firstly, the RL system was successfully developed with innovative application in a few science experiments; it can be used inside or outside the school environment to enhance the science learning and complements the regular classroom teaching processes. Secondly, the comparison of students' perceptions of the RL and the conventional science laboratory serves a reference point for the future development of an educationally sound RL system. Moreover, the comments and suggestions for improvement of the RL with the IP camera were collected for refinement. By applying the iteration process of DBR through design, implementation, analysis and refinement, we have refined our RL system and design principles. As the refined RL system will likely have some significant implications in science education, it should be further tested in the secondary school environment.

As science teaching and learning is shifting towards a new direction, we anticipate that a more studentcentred learning approach will be engaged and made possible through the effective use of digital technology: especially in the way students conduct science experiments. Recent education reforms have identified the importance of technology-enhanced science learning, which can be achieved in science education through the RL system (Kong et al., 2009; Lowe et al., 2013). Therefore, the development of RL will become an important feature of science practical work and a demonstration kit for future teaching and learning of science, especially for those processes which are impossible to implement in a traditional school learning environment.

In summary, this study reports how we successfully developed and evaluated the RL system together with an IP camera in the design of several feasible experiments involving sound, electric circuit connection, phototropism, and day and night-time gravitropism, in addition to the refinement of various remote experiments. 


\section{Acknowledgements}

We are very grateful to The Hong Kong Institute of Education and Research Grants Council of Hong Kong in a related project for financial support, particularly for the provision of a PhD scholarship to S. W. Tho. Special thanks are also due to Professor Peter Tanner for his helpful comments on the manuscript.

\section{References}

Abdulwahed, M., \& Nagy Z. K. (2011). The TriLab, a novel ICT based triple access mode laboratory education model. Computers \& Education, 56(1), 262-274. http://dx.doi.org/10.1016/j.compedu.2010.07.023

Abrahams, I., \& Reiss, M. J. (2012). Practical work: Its effectiveness in primary and secondary schools in England. Journal of Research in Science Teaching, 49(8), 1035-1055. http://dx.doi.org/10.1002/tea.21036

Amiel, T., \& Reeves, T. C. (2008). Design-based research and educational technology: Rethinking technology and the research agenda. Educational Technology \& Society, 11(4), 29-40. Retrieved from http://www.ifets.info/download_pdf.php?j_id=41\&a_id=887

Anderson, T. (2005). Design-based research and its application to a call centre innovation in distance education. Canadian Journal of Learning and Technology, 31(2). Retrieved from http://www.cjlt.ca/index.php/cjlt/article/view/143/136

Anderson, T., \& Shattuck, J. (2012). Design-based research: A decade of progress in education research? Educational Researcher, 41(1), 16-25. http://dx.doi.org/10.3102/0013189X11428813

Baker, T. A. (2007). An open-source program to animate and visualize the recorded temperature and relative humidity data from dataloggers including the building's three-dimensional geometry (Master's thesis). Retrieved from ProQuest Dissertations \& Theses. (UMI Number: 1447038)

Barrios, A., Panche, S., Duque, M., Grisales, V. H., Prieto, F., Villa, J. L., et al. (2013). A multi-user remote academic laboratory system. Computers \& Education, 62, 111-122. http://dx.doi.org/10.1016/j.compedu.2012.10.011

Barton, R. (2004). Teaching secondary science with ICT. Maidenhead: Open University Press.

Chen, S., Lo, H. C., Lin, J. W., Liang, J. C., Chang, H. Y., Hwang, F. K., et al. (2012). Development and implications of technology in reform-based physics laboratories. Physical Review Special TopicsPhysics Education Research, 8(2), 020113-1-12. http://dx.doi.org/10.1103/PhysRevSTPER.8.020113

Cheung, D. (2008). Facilitating chemistry teachers to implement inquiry-based laboratory work. International Journal of Science and Mathematics Education, 6(1), 107-130. http://dx.doi.org/10.1007/s10763-007-9102-y

Collins, A. (1992). Toward a design science of education. In E. Scanlon \& T. O'Shea (Eds.), New directions in educational technology (pp. 15-22). New York, NY: Springer-Verlag.

Cooper, M., \& Ferreira, J. M. (2009). Remote laboratories extending access to science and engineering curricular. IEEE Transactions on Learning Technologies, 2(4), 342-353. http://dx.doi.org/10.1109/TLT.2009.43

Design-Based Research Collective. (2003). Design-based research: An emerging paradigm for educational inquiry. Educational Researcher, 32(1), 5-8. http://dx.doi.org/10.3102/0013189X032001005

Feng, W., \& Hannafin, M. J. (2005). Design-based research and technology-enhanced learning environments. Educational Technology Research \& Development, 53(4), 5-23. http://dx.doi.org/10.1007/BF02504682

Gallet, C. (1998). Problem solving teaching in the chemistry laboratory: Leaving the cooks .... Journal of Chemical Education. 75(1), 72-75. http://dx.doi.org/10.1021/ed075p72

Gillet, D., Ngoc, A., \& Rekik, Y. (2005). Collaborative web-based experimentation in flexible engineering education. IEEE Transactions on Education, 48(4), 696-704. http://dx.doi.org/10.1109/TE.2005.852592

Grober, S., Vetter, M., Eckert, B., \& Jodl, H. (2007). Experimenting from a distance--remotely controlled laboratory (RCL). European Journal of Physics, 28(3), 127-141. http://dx.doi.org/10.1088/0143$\underline{0807 / 28 / 3 / \mathrm{S} 12}$

Gustavsson, I., Nilsson, K., Zackrisson, J., Garcia-Zubia, J., Hernandez-Jayo, U., Nafalski, A., ... \& Hkansson, L. (2009). On objectives of instructional laboratories, individual assessment, and use of 
collaborative remote laboratories. IEEE Transactions on Learning Technologies, 2(4), 263-274. http://dx.doi.org/10.1109/TLT.2009.42

Hercog, D., Gergič, B., Uran, S., \& Jezernik, K. (2007). A DSP-based remote control laboratory. IEEE Transactions on Industrial Electronics, 54(6), 3057-3068. http://dx.doi.org/10.1109/TIE.2007.907009

Hofstein, A., \& Lunetta, V. N. (2004). The laboratory in science education: Foundations for the twentyfirst century. Science Education, 88(1), 28-54. http://dx.doi.org/10.1002/sce.10106

Hofstein, A., \& Mamlok-Naaman, R. (2007). The laboratory in science education: The state of the art. Chemistry Education Research and Practice, 8(2), 105-107. http://dx.doi.org/10.1039/B7RP90003A

Jona, K., Roque, R., Skolnik, J., Uttal, D., Rapp, D. (2011). Are remote labs worth the cost? Insights from a study of student perceptions of remote labs. International Journal of Online Engineering, 7(2), 4853. Retrieved from http://online-journals.org/index.php/i-joe/article/view/1394/1754

Jona, K., \& Vondracek, M. (2013). A remote radioactivity experiment. The Physics Teacher, 51(1), 2527. http://dx.doi.org/10.1119/1.4772033

Jonassen, D. H. (1999). Designing constructivist learning environments. In C. M. Reigeluth (Ed.), Instructional design theories and models: A new paradigm of instructional theory (Vol. 2) (pp. 215239). New York, NY: Routledge.

Kirschner, P. A., Sweller, J., \& Clark, R. E. (2006). Why minimal guidance during instruction does not work: An analysis of the failure of constructivist, discovery, problem-based, experiential, and inquirybased teaching. Educational Psychologist, 41(2), 75-86. http://dx.doi.org/10.1207/s15326985ep4102_1

Ko, C. C., Chen, M., Chen, J. P., Zhuang, Y., \& Tan, K. C. (2001). Development of a web-based laboratory for control experiments on a coupled tank apparatus. IEEE Transactions on Education, 44(1), 76-86. http://dx.doi.org/10.1109/13.912713

Kong, S. C., Yeung, Y. Y., \& Wu, X. (2009). An experience of teaching for learning by observation: Remote-controlled experiments on electrical circuits. Computers \& Education, 52(3), 702-717. http://dx.doi.org/10.1016/j.compedu.2008.11.011

Lowe, D., Newcombe, P., \& Stumpers, B. (2013). Evaluation of the use of remote laboratories for secondary school science education. Research in Science Education, 43(3), 1197-1219. http://dx.doi.org/10.1007/s11165-012-9304-3

Nagaraju, M. T. V. (2008). Handbook for teaching physical sciences: Methods and techniques. New Delhi: Kanishka.

National Instruments. (2011). LabVIEW 2011 SP1. Retrieved from http://www.ni.com

National Research Council. (2012). A framework for K-12 science education: Practices, crosscutting themes, and core ideas. Washington, DC: National Academies Press.

Ng, P. H., \& Yeung, Y. Y. (2000). Implications of data-logging on A.L. physics experiments: A preliminary study. Asia-Pacific Forum on Science Learning and Teaching, 1(2), Article 5. Retrieved from http://www.ied.edu.hk/apfslt/issue_2/phng/

Reddy, R., \& Goodman, P. S. (2002). Technology trends and implication for learning in tertiary institutions. In P. S. Goodman (Ed.), Technology enhanced learning: Opportunities for change (pp. 3-20). Mahwah, NJ: Erlbaum.

Reeves, T. (2006). Design research from a technology perspective. In J. V. D. van den Akker, K. Gravemeijer, S. McKenney, \& N. Nieveen (Eds.), Educational design research (pp. 52-66). New York, NY: Routledge.

Roth, W. M. (1994). Experimenting in a constructivist high school physics laboratory. Journal of Research in Science Teaching, 31(2), 197-223. http://dx.doi.org/10.1002/tea.3660310209

Sauter, M., Uttal, D. H., Rapp, D. N., Downing, M., \& Jona, K. (2013). Getting real: The authenticity of remote labs and simulations for science learning. Distance Education, 34(1), 37-47. http://dx.doi.org/10.1080/01587919.2013.770431

Scanlon, E., Colwell, C., Cooper, M., \& Di Paolo, T. (2004). Remote experiments, re-versioning and rethinking science learning. Computers and Education, 43(1/2), 153-164. http://dx.doi.org/10.1016/j.compedu.2003.12.010

Schauer, F., Lustig, F., Dvořák, J., \& Ožvoldová, M. (2008). An easy-to-build remote laboratory with data transfer using the Internet School Experimental System. European Journal of Physics, 29(4), 753-765. http://dx.doi.org/10.1088/0143-0807/29/4/010

Souter, N., \& MacVicar, G. (2012). Smartphones, time-lapse and responsible use in the school laboratory. School Science Review, 94(347), 11-13. Retrieved from https://www.ase.org.uk/journals/school-science-review/2012/12/347/3228/ssr-december-2012-011013-souter-macvicar-science-note.pdf 
Steinberg, R. (2003). Effects of computer-based laboratory instruction on future teachers' understanding of the nature of science. Journal of Computers in Mathematics \& Science Teaching, 22(3), 185-205. Retrieved from http://www.editlib.org/p/12788

Tawfik, M., Sancristobal, E., Martin, S., Gil, R., Diaz, G., Colmenar, A., ... \& Gustavsson, I. (2013). Virtual Instrument Systems in Reality (VISIR) for remote wiring and measurement of electronic circuits on breadboard. IEEE Transactions on Learning Technologies, 6(1), 60-72. http://dx.doi.org/10.1109/TLT.2012.20

Taylor, H. R. (1997). Data acquisition for sensor systems. London: Chapman \& Hall.

Tho, S. W., \& Hussain, B. H. (2011). The development of a microcomputer-based laboratory (MBL) system for gas pressure law experiment via open source software. International Journal of Education and Development using ICT, 7(1), 42-55. Retrieved from http://ijedict.dec.uwi.edu/viewarticle.php?id=1202

Tho, S. W., \& Yeung, Y. Y. (2014a). Innovative use of smartphones for sound resonance tube experiment. Teaching Science, 60(1), 39-42. Retrieved from http://search.informit.com.au/documentSummary;dn=885255020026296;res=IELHSS

Tho, S. W., \& Yeung, Y. Y. (2014b). Remote laboratory (RL) system for technology-enhanced science learning: The design and pilot implementation in undergraduate courses. In C. C. Liu, H. Ogata, S. C. Kong, \& A. Kashihara (Eds.), Proceedings of the 22nd International Conference on Computers in Education, ICCE 2014 (pp. 260-262_. Retrieved from http://icce2014.jaist.ac.jp/icce2014/wpcontent/uploads/2015/08/ICCE2014-Main-Proceedings-lite.pdf

Tho, S. W., \& Yeung, Y. Y. (2015). Innovative IP camera applications for scientific investigation. School Science Review, 96(356), 58-62. Retrieved from https://www.ase.org.uk/journals/school-sciencereview/2015/02/356/3818/ssr-march-2015-058-062-tho-yeung.pdf

Tiwari, R., \& Singh, K. (2011). Virtualisation of engineering discipline experiments for an Internet-based remote laboratory. Australasian Journal of Educational Technology, 27(4), 671-692. http://dx.doi.org/10.14742/ajet.944

Torre, L., Heradio, R., Jara, C., Sanchez, J., Dormido, S., Torres, F., \& Candelas, F. (2013). Providing collaborative support to virtual and remote laboratories. IEEE Transactions on Learning Technologies, 6(4), 312-323. http://dx.doi.org/10.1109/TLT.2013.20

Yeung, Y. Y., Lee, Y. C., \& Lam, C. M. (2012). Curriculum reform and restructuring of senior secondary science education in Hong Kong: Teachers’ perceptions and implications. Asia-Pacific Forum on Science Learning and Teaching, 13(2), Article 11. Retrieved from http://www.ied.edu.hk/apfslt/v13_issue2/yeungleelam/

Corresponding author: Siew Wei Tho, thosw82@s.eduhk.hk \& thosw@fsmt.upsi.edu.my

Australasian Journal of Educational Technology (c) 2016.

Please cite as: Tho, S. W., \& Yeung, Y. Y. (2016). Technology-enhanced science learning through remote laboratory: System design and pilot implementation in tertiary education. Australasian Journal of Educational Technology, 32(3), 96-111. 